\title{
Mycobacterium avium subsp. paratuberculosis lipophilic antigen causes Crohn's disease-type necrotizing colitis in Mice
}

\author{
Eiichi Momotani ${ }^{1 *}$, Hiroshi Ozaki ${ }^{2}$, Masatoshi Hori ${ }^{2}$, Shizuo Yamamoto ${ }^{3}$, Takashi Kuribayashi ${ }^{3}$, Shigetoshi Eda ${ }^{4}$ \\ and Masahiro Ikegami ${ }^{5}$
}

\begin{abstract}
Background: A 2,4,6-trinitrobenzene sulfonic acid (TNBS)-induced murine colitis model was developed to investigate the pathogenesis and to evaluate a method of treating human Crohn's disease. This experimental model rapidly induces colitis similar to human Crohn's disease lesion in a reproducible manner. However, natural exposure of the human digestive tract to TNBS is unrealistic. A novel animal model based on realistic data is eagerly anticipated in future research on pathogenesis of CD. Method: We evaluated the potency of Map antigen molecules in an effort to develop a novel colitis model using a more realistic source than TNBS. We prepared the Map antigen by ethanol extraction and developed a mouse model in a manner similar to that of the well-known TNBS-induced colitis in mice. In the experiment, seven days after subcutaneous (SC) injection of the antigen into normal C57BL/6 mice, the same antigen in 50\% ethanol was injected into the colon by the transanal route with a fine cannula. Results: On the fifth day after the transanal injection, histopathological examination revealed full-thickness necrotizing colitis with erosion and ulcers; severe infiltration with neutrophils, lymphocytes, macrophages, and perforation. However, no change was detected with each single Map-antigen injection. Conclusion: The present results provide a novel animal model for research on CD and may be the key to clarifying the relationship between CD and Map. This is the first evidence that mycobacterium antigen induces necrotizing colitis.
\end{abstract}

Keywords: Mycobacterium, Paratuberculosis, Crohn's disease, IBD, Mice, Necrotizing colitis, TNBS

\section{Background}

The number of studies attempting to detect clues to the mystery of Crohn's disease (CD), a chronic intractable intestinal disease, has recently increased (Lakatos 2009; Momotani et al. 2012; Simmons 2010). Althoug various symptomatic treatments and approaches to diet restriction half of $\mathrm{CD}$ patients require surgery within 10 years after diagnosis. The risk of postoperative recurrence is 44 to 55\% after 10 years (Peyrin-Biroulet et al. 2010). The globally rising rate of pediatric $\mathrm{CD}$ is also a major issue (Benchimol et al. 2011; Jakobsen et al. 2008; Phavichitr et al. 2003). No convincing explanation of the pathogenesis of CD currently exists; however, various environmental factors (e.g., pathogenic or non-pathogenic microbes,

\footnotetext{
* Correspondence: eiichimomotani@gmail.com

${ }^{1}$ Research Area of Pathology and Pathophysiology, National Institute of Animal Health, 3-1-5 Kan-nondai, Tsukuba 305-0856, Japan Full list of author information is available at the end of the article
}

lifestyle, hygiene factors, diet, and stress) have been suggested (Economou and Pappas 2008; Glasser and Darfeuille-Michaud 2008; Lakatos 2009; Momotani et al. 2012; Neuman and Nanau 2012). Responsible host genes such as the famous NOD2 and a genetic predisposition to $\mathrm{CD}$ have been suspected as well (Economou and Pappas 2008; Glasser and Darfeuille-Michaud 2008; Umeno et al. 2011; Vora et al. 2012). The focus in recent years has been on Mycobacterium avium subsp. paratuberculosis (Map) (Behr and Kapur 2008; Eltholth et al. 2009; Momotani et al. 2012), due to the reported pathological similarities of $\mathrm{CD}$ and paratuberculosis (Ptb), accumulating reports of frequent detection of Map IS900 DNA, and much less isolation of Map from CD lesions (Abubakar et al. 2008; Chiodini 1989; Feller et al. 2007; Momotani et al. 2012). Detection of live Map and Map IS900 DNA in children with early-onset CD has been reported (Kirkwood et al. 2009).

\section{实}


Paratuberculosis is a chronic and progressive granulomatous enteritis that affects livestock and wild animals worldwide (Chiodini et al. 1984; Momotani et al. 2012; Nielsen and Toft 2009; Raizman et al. 2009; Stabel et al. 2009). However, differences between CD and Ptb have been pointed out (Momotani et al. 2012; Van Kruiningen 1999). An additional mystery is the "invisible Map" that supposedly grows in CD lesions (Momotani et al. 2012; Pierce 2009; Van Kruiningen 1999). This phenomenon has been explained by isolation of a cell-wall-deficient, spheroplastic form of Map from human CD lesions (Wall et al. 1993). However, even immunohistochemical staining for cytoplasmic and cell-wall components of Map could not detect Map in CD lesions (Kobayashi et al. 1989; Momotani et al. 2012; Pierce 2009; Sartor 2005; Van Kruiningen 1999). In contrast to the hypothesis that Map infection causes CD, there are no reports of CD-like Ptb lesions in natural or experimental infection with Map (Chiodini 1989; Chiodini et al. 1984). Furthermore, intestinal lesions in Ptb of cynomolgus were very similar to those of bovine but differed histopathologically from human CD (McClure et al. 1987).

An experimental colitis model using mice or rats with haptenizing agent 2,4,6-trinitrobenzene sulfonic acid (TNBS) yields pathological findings similar to those of human CD (Arita et al. 2005; Neurath et al. 2000; te Velde et al. 2006). However, natural exposure of the human digestive tract to TNBS is unrealistic. In contrast, exposure of the human digestive tract to Map antigen is realistic (Behr and Kapur 2008; Eltholth et al. 2009; Over et al. 2011), since frequently detected Map IS900 DNA in CD patients (Abubakar et al. 2008; Chiodini 1989; Feller et al. 2007; Momotani et al. 2012) is considered to be evidence of Map antigen exposure, rather than Map infection. In the present study, we prepared a lipophilic antigen of Map, and TNBS in the previous TNBS colitis model (Arita et al. 2005) was replaced with the Map antigen. Histopathological evaluation revealed severe necrotizing colitis that is very similar to that in the wellknown TNBS colitis model. The present study proposes a new CD model and a novel hypothesis on the pathogenesis of human $\mathrm{CD}$.

\section{Results}

\section{Clinical findings and gross pathology}

During the experiment period, only a few mice exhibited inactivation and a rough coat. During the autopsy, thickening of the colon wall with congestion was observed in the 6 cases exhibited total score than 15 (Figure 1A).

\section{Histopathology}

Stacked bar graphs present histopathological findings regarding degree (Figure 1B), distribution of lesions (Figure 1B), and types of infiltrating cells (Figure 1C).
All sections were stained with hematoxylin and eosin $(\mathrm{H} \& \mathrm{E})$, and the magnification of photos is indicated as a bar.

\section{Group 1}

Histopathological findings caused by TNBS are presented in Figure 2. Three severe (cases T3-5, Figure 2A) and two mild (cases T1 and 2, Figure 2A) colitis cases were observed. Case T-4 exhibited the most severe fullthickness necrotizing colitis (Figure 2A-D). The most severely damaged tissue was shaped like an erupting volcano (Figure 2A, arrow). The colitis included various degrees of erosion, ulceration, and infiltration with neutrophils, lymphocytes, and macrophages in laminapropria mucosa (Figure 2B-F). Atypical epithelial cells including irregularly shaped, vacuolated, and regenerating cells were observed (Figure 2B-F). Epithelium was sometimes infiltrated with neutrophils (Figure 2C, arrows). Granulation (g), an early stage of fibrosis, was observed with ulcer formation (Figures $2 \mathrm{~B}$ and $\mathrm{C}$ ). Intestinal epithelial cells and crypt (c) structure on the necrotizing area disappeared or were modified by inflammation and granulation (Figure 2B-F). Neutrophils were the predominant infiltrating cells (Figure 2C); however, other cell types also contributed. Edema (ed) of the muscle layer (m) was observed (Figure 2A and B). Medium infiltration and edema (ed) in the lamina propria mucosa and sub-mucosa (sm) were observed (Figure 2D). Erosion and ulceration were observed in cases T-2 (Figure 2E) and T-3 (Figure 2F).

\section{Group 2}

Histopathological findings of group 2 are presented in Figure 3. The most severe findings (Figures 3A-F) were observed in case M100-2. Figures $3 \mathrm{G}$ and $\mathrm{H}$ are from case M100-3. Case M100-2 exhibited severe fullthickness destructive enteritis (Figures 3A-F). The most severe changes were deep ulcer and necrotizing enteritis (ne) (Figures 3A and B). Accumulation of inflammatory cells (aic), debris, and edema (e) were seen as a pseudomembrane (Figures $3 \mathrm{~A}$ and $\mathrm{B}$ ). The normal structure of the mucosa completely disappeared (Figure 3, arrow); however, the severity differed from area to area for the same case (Figures $3 \mathrm{~A}$ and $\mathrm{B}$ ). In some areas of the colon, the structure of the epithelium was maintained, but infiltration and edema were characteristically observed in the muscle layer (ml) (Figures $3 \mathrm{C}$ and D). Cellular infiltration is observed between circular muscular fibers (Figure 3E). Edema and cellular infiltration of the longitudinal muscle $(\mathrm{lm})$ and the serosal membrane (Figures 3D and F) were observed. Fibrin deposition (f) was observed on the serosal membrane (sm) (Figure 3F). Full-thickness necrotizing enteritis was observed in case M100-3 (Figure 3G). The pseudomembrane $(\mathrm{pm})$ was also observed (Figure 3F). Infiltration in 

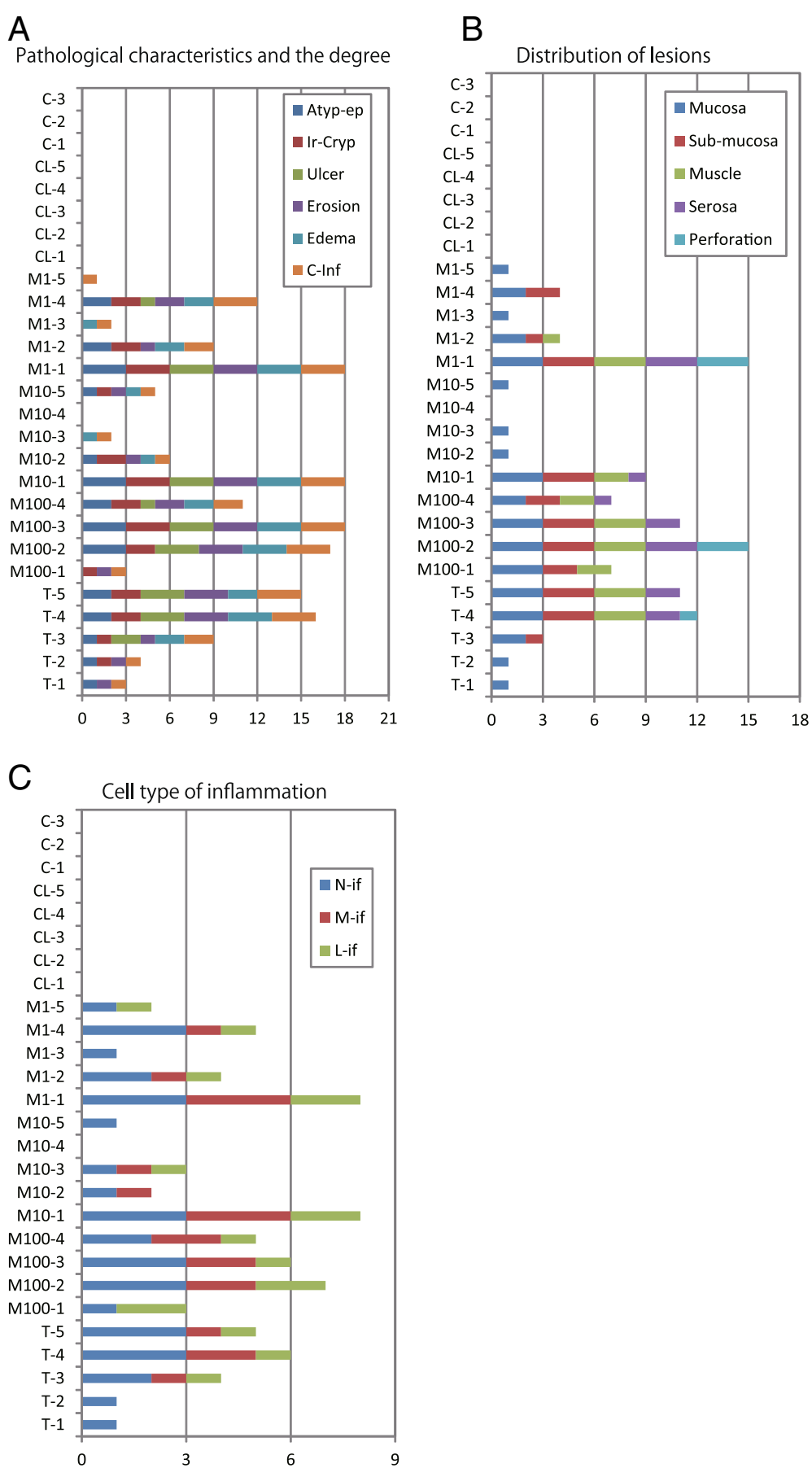

Figure 1 A. Histopathological data of experimental enteritis generated by TNBS and Mycobacterium avium subsp. paratuberculosis antigen in C57BL/6 mice. The longitudinal axis represents types of treatment and numbers of mice. C: Control injected with only vehicle. $\mathrm{CL}$ : Mice injected subcutaneously (SC) with vehicle and with MAP-L100 antigen via the intra-colon (IC) route. M1: Mice injected subcutaneously with MAP-I00 plus MAP-L1 via the IC route. M10: Mice injected subcutaneously with MAP-I00 and with MAP-L10 via the IC route. M100: Mice injected subcutaneously with MAP-100 and with MAP-L100 via the IC route. T: Mice injected subcutaneously with $2.5 \%$ TNBS and with $10 \%$ via the IC route. Color bars indicate the type of lesion: Atypical epithelial cells (Atyp-ep), irregularly shaped crypt (Ir-Cryp), ulcer (Ulcer), erosion (Erosion), edema (Edema), and cellular infiltration (C-inf). The length of each color bar indicates the intensity (index 0 to 3). The total length of the color bar (horizontal axis) indicates the total degree of enteritis. B. Distribution of lesions in lamina propria mucosa (Mucosa), sub-mucosa, muscle layer (Muscle), serosa, and perforation. The degree of lesion (index 0 to 3 ) in each layer is denoted by the length of the bar. $\mathbf{C}$. The type of inflammatory cell (neutrophil (N-if), macrophage (M-if), or lymphocyte (L-if)) is denoted by color, and the degree is denoted by the length of the bars. 


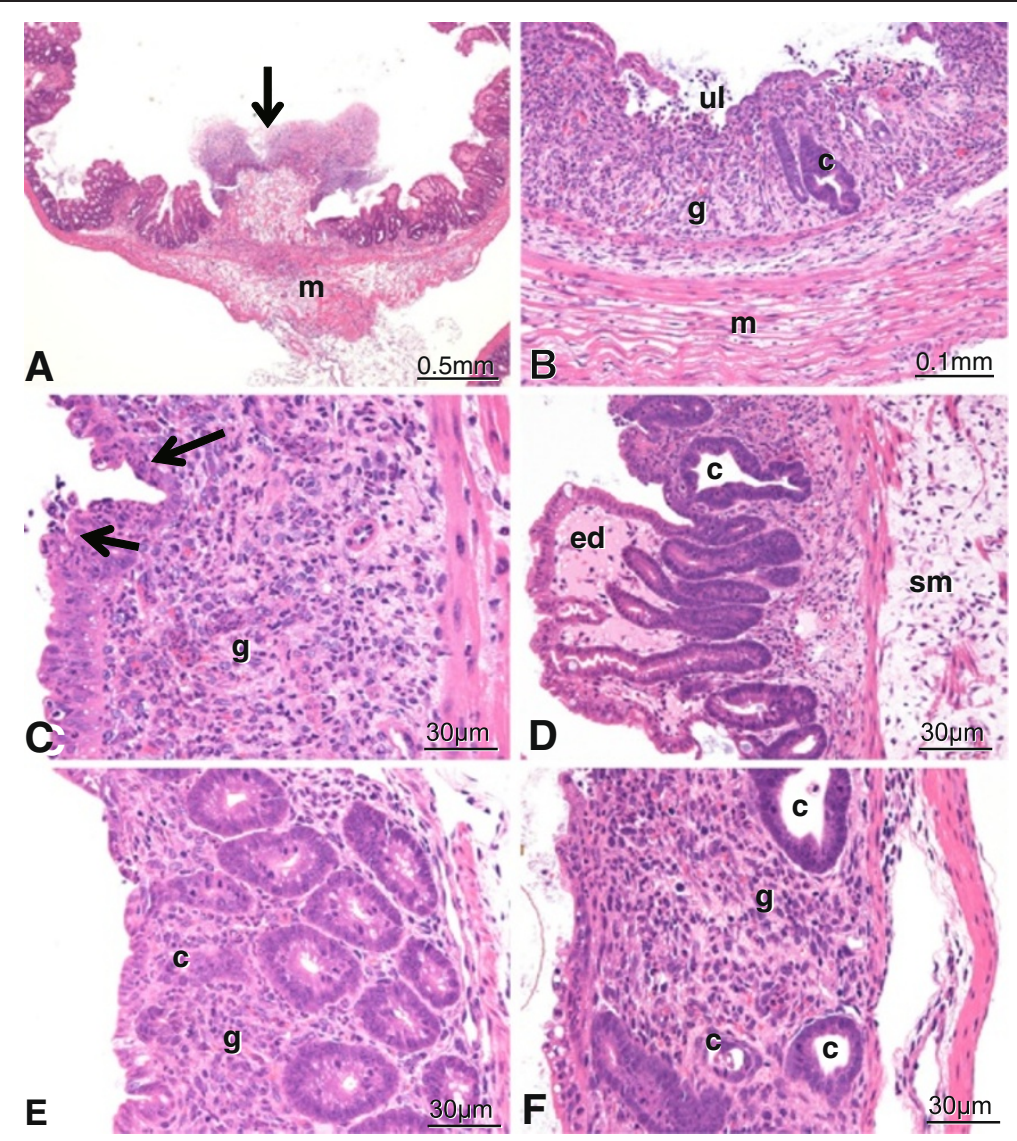

Figure 2 Histopathology of group 1. Case T-4 exhibits very severe full-thickness necrotizing enteritis (Figures 2A-D). The most severely damaged tissue is shaped like an erupting volcano (Figure $2 \mathbf{A}$, arrow). Other areas are irregularly shaped. Erosion, ulceration, and granulation ( $\mathrm{g}$ ) are seen (Figures $\mathbf{2} \mathbf{B}$ and $\mathbf{C}$ ). Intestinal epithelial cells and crypt(c) structure disappear or are modified by inflammation and organization (Figures 2B-D). Neutrophils are the predominant infiltrating cells (Figure 2C). Edema of the muscle layer $(\mathrm{m})$ is observed (Figures $2 \mathbf{A}$ and $\mathbf{B}$ ). Medium infiltration and edema in the lamina propria mucosa and sub-mucosa (sm) are observed to vary by area (Figure 2D). Erosion and ulceration are seen in T2 (Figure 2E) and 3 (Figure 2F). Crypt (c) structure is irregularly shaped or disappears due to inflammation and granulation (g) (Figures 2E and F).

the muscle layer was severe (Figure 3G). Cellular infiltration and granulation tissue were observed with ulcer (ul) formation (Figure $3 \mathrm{H}$ ).

\section{Group 3}

The histopathology of group3 is presented in Figure 4. Figures $4 \mathrm{~A}$ and $\mathrm{B}$ are from case M10-1. Figures $4 \mathrm{C}$ and $\mathrm{D}$ are from case M10-2. In M10-1, severe destructive inflammation and development of granulation tissue were observed with ulcer formation (Figure 4A). Cellular infiltration was observed mainly in the laminapropria mucosa $(\mathrm{lm})$ and sub-mucosa ( $\mathrm{sm})$ but was not severe in the muscular layer $(\mathrm{ml})$ (Figure 4A). Tissue detached by coagulation necrosis $(\mathrm{cn})$ is depicted in Figure 4A. Other areas of the colon exhibited erosion (er), edema (e), mild cellular infiltration, and irregular crypt (ic) structures (Figure 4B). Case M10-2 exhibited a small ulcer (ul), erosion (er), cellular infiltration, and irregular crypt (ic); however, no severe necrotizing lesions were apparent (Figures $4 \mathrm{C}$ and D).

\section{Group 4}

The histopathology of the colon section in C57BL/6 mice SC injected with MAP-L100 antigen and then with MAP-L1 via the IC route is depicted in Figures 5A-F. Figures 5A-D are from case M1-1. Figures $5 \mathrm{E}$ and $\mathrm{F}$ are from case M1-4. Figure 5A indicates very severe fullthickness necrotizing enteritis shaped like an erupting volcano (ve). Edema (ed) and cellular infiltration (ci) of the laminapropria mucosa and sub-mucosa (Figures 5B and $C$ ) and atrophy of the crypt were observed (Figures 5C and D). The component cell types of the infiltration are neutrophil, macrophage, and lymphocyte (Figure 5D). Small erosion (e) and cellular infiltration (ci) are seen in the laminapropria mucosa and submucosa (Figures 5E and F). 


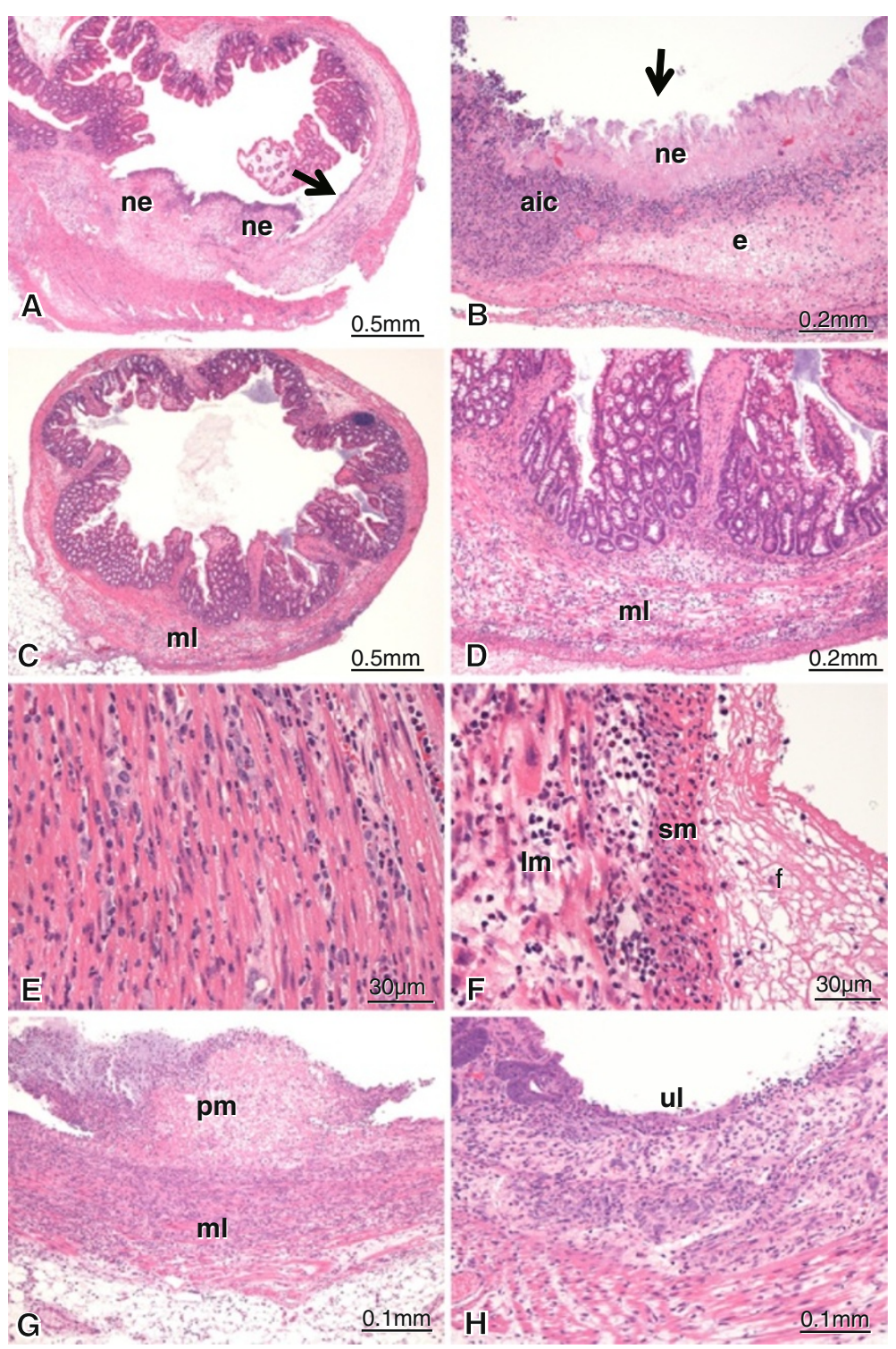

Figure $\mathbf{3}$ Histopathology of group 2. Figures $3 \mathbf{A}-\mathbf{F}$ are from case M100-2. Figures $3 \mathbf{G}$ and $\mathbf{H}$ are from case M100-3. All sections were stained with hematoxylin and eosin (H\&E), and the magnification is denoted by a bar. Case M100-2 exhibited severe full-thickness destructive enteritis (Figures 3A-F). The most severe change was deep ulceration and necrotizing enteritis (ne) (Figures 3A and B). Accumulation of inflammatory cells (aic) and debris, and edema (e) are seen as a pseudomembrane (Figures $3 \mathbf{A}$ and $\mathbf{B}$ ). The normal structure of the mucosa completely disappeared (arrows); however, the severity differed from area to area in the same case. The structure of the epithelium was maintained in some areas of the colon, but infiltration and edema were observed in the muscle layer ( $\mathrm{ml}$ ) (Figures $3 \mathbf{C}$ and $\mathbf{D}$ ). Cellular infiltration was observed between circular muscular fibers (Figure 3E). Edema and cellular infiltration of the longitudinal muscle (Im) and serosal membrane occurred (Figure 3F). Fibrin deposition ( $f$ ) was observed on the serosal membrane (sm) (Figure 3F). Full-thickness necrotizing enteritis is seen in case M100-3 (Figure 3G). Pseudomembrane (pm) is observed (Figure 3F). Infiltration in the muscle layer is significant (Figure 3G). Cellular infiltration and granulation tissue are observed where ulcers (ul) form (Figure $3 \mathbf{H}$ ).

\section{Groups 5 and 6}

No lesion was observed in group 5 (Figure 6A) and in group 6 (Figure 6B).

\section{Discussion}

The present study provides the first evidence that the Map antigen has the potency to induce colitis that is very similar to mouse TNBS-induced colitis, which has been used as an experimental Crohn's disease model (Arita et al. 2005; Neurath et al. 2000; te Velde et al. 2006). The nature of the inflammation observed in the present study was very different from that of natural Ptb inflammation (Chiodini et al. 1984; Veazey et al. 1995), but rather similar to human Crohn's disease enteritis (Loddenkemper 2009; 


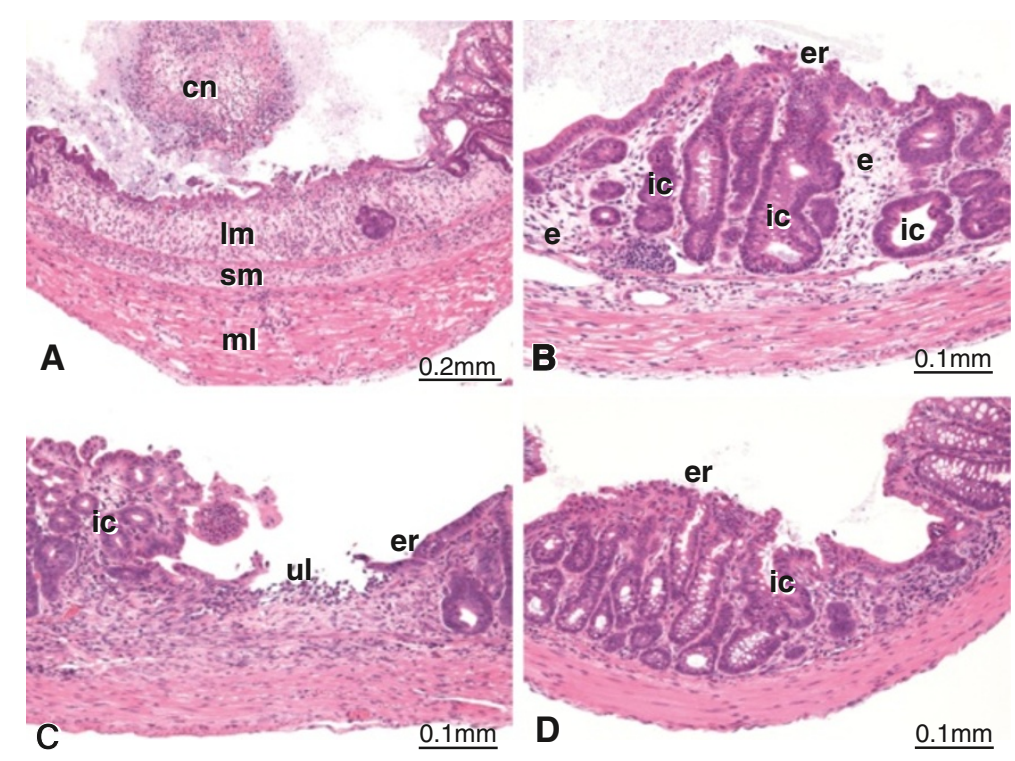

Figure 4 Histopathology of group 3. Figures $4 \mathbf{A}$ and $\mathbf{B}$ are from case M10-1. Figures $4 \mathbf{C}$ and $\mathbf{D}$ are from case M10-2. In M10-1, severe destructive inflammation and development of granulation tissue, and tissue detached by coagulation necrosis (cn) were observed with ulcer formation (Figure 4A). Cellular infiltration was observed mainly in the laminapropria mucosa $(\mathrm{Im})$ and sub-mucosa (sm) but was not severe in the muscular layer (ml) (Figure 4A).Other areas of the colon exhibited erosion (er), edema (e), mild cellular infiltration, and irregular crypt (ic) structures (Figure 4B). Case M10-2 exhibited a small ulcer (ul), erosion (er), cellular infiltration, and irregular crypt (ic); however, no severe necrotizing lesions were apparent.

Momotani et al. 2012). However, granuloma formation, a characteristic finding in CD (Loddenkemper 2009; Momotani et al. 2012), was not observed in Map-L and TNBSinduced acute phase colitis in the present study. This finding coincided with previous findings in the study of acute TNBS colitis (Arita et al. 2005; Neurath et al. 2000; te Velde et al. 2006; Wirtz et al. 2007). The necrotizing colitis consisted of erosion, ulceration, and infiltration with neutrophil, lymphocyte, and macrophage. Development of ulceration and regeneration by granulation tissue was also observed. The damaged tissues were restricted, and the adjacent area indicated normal or mild changes in the present TNBS- and Map-induced colitis. The finding that the changes may be somewhat similar to "skip lesions" is important in differentiating CD from UC (Wakefield et al. 1989). Every characteristic change in TNBS-induced colitis was observed in the present Map antigen-induced lesions. However, cellular infiltration in the muscular layer in Map antigeninduced colitis was more prominent than in TNBSinduced colitis (Arita et al. 2005; Neurath et al. 2000; te Velde et al. 2006). In human CD enteritis, severe cellular infiltration or lymphoid follicle formation in the muscular layer is very common (Baumgart and Sandborn 2007; Loddenkemper 2009; Momotani et al. 2012). This Map-induced colitis may be closer to human CD lesions than TNBS-induced colitis.

This is the first objective attempt to produce necrotizing colitis by mycobacterial antigen. The results suggest the novel etiological relationship of Map to human CD. Traditional etiological studies on $\mathrm{CD}$ and Map have been carried out under the hypothesis that "Map infection" causes CD (Behr and Kapur 2008; Gill et al. 2011; Hermon-Taylor et al. 2000). The effect of a "Map antigen" that can contaminate dairy products (Eltholth et al. 2009; Foods 2010; Hermon-Taylor et al. 2000; Millar et al. 1996; Patel and Shah 2011) and meat (Alonso-Hearn et al. 2009; Gill et al. 2011; Klanicova et al. 2011) from Ptb-infected cattle on human health was not reflected as an etiology of CD (Economou and Pappas 2008; Glasser and Darfeuille-Michaud 2008; Lakatos 2009; Umeno et al. 2011). As many previous studies have indicated, the detection of Map-specific DNA IS900 by PCR from human intestine, blood, and feces (Abubakar et al. 2008; Chiodini 1989; Tuci et al. 2011) or by in situ hybridization in intestines (Romero et al. 2005) may be evidence of exposure to the Map antigen complex but does not always mean the presence of live Map. The present results may solve the problem of meeting a requirement of Koch's postulates in analyzing the relationship between CD and Map (Lowe et al. 2008).

The facts that colitis in the present study occurred only with repeated exposure to the Map antigen and that similar histopathological characteristics were observed after a second exposure to the Map antigen in different concentrations suggest the contribution of an immunological mechanism, presumably a delayed-type hypersensitivity (DTH) reaction (Black 1999; Kobayashi et al. 2001). Similar pathogenesis has been considered in 


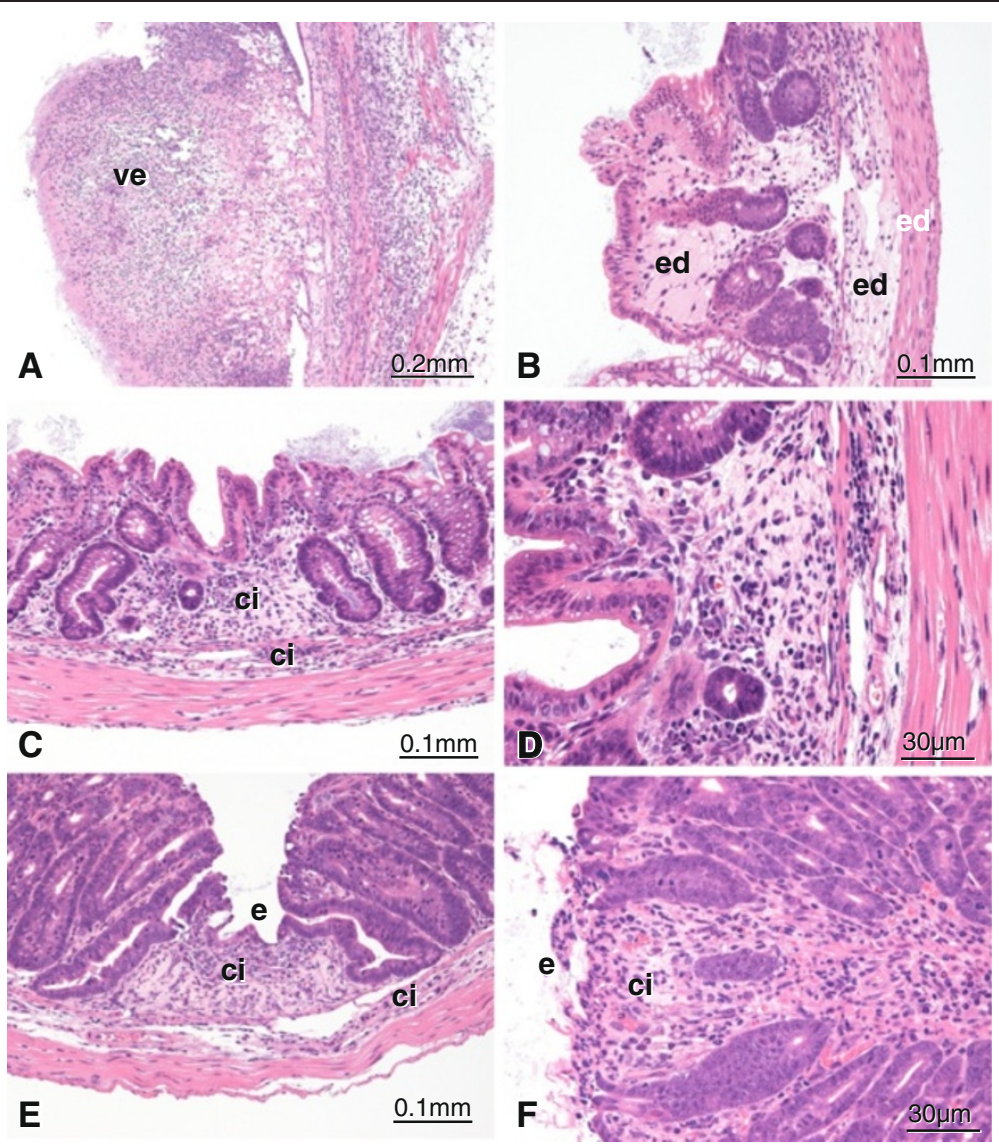

Figure 5 Histopathology of group 4. Figure $5 \mathbf{A}-\mathbf{D}$ are from case M1-1. Figures $5 \mathbf{E}$ and $\mathbf{F}$ are from case M1-4. All sections were stained with $\mathrm{H} \& \mathrm{E}$, and the magnification is indicated by a bar. Figures $5 \mathbf{A}$ indicates very severe full-thickness necrotizing enteritis shaped like an erupting volcano (ve) (Figures 5A). Edema (ed) and cellular infiltration (ci) laminapropria mucosa and sub-mucosa are seen (Figures 5B and C). The crypt atrophies (Figures 5C and D). Component cell types are neutrophils, macrophages, and lymphocytes (Figure 5D). Minor erosion (e) and cellular infiltration (ci) are seen in laminapropria mucosa and sub-mucosa (Figures 5E).

TNBS colitis (te Velde et al. 2006). However, further molecular pathological studies are necessary. Recent reports on Map-specific reactive CD4 $\mathrm{T}$ cells in $\mathrm{CD}$ patients (Olsen et al. 2009) suggest the contribution of a DTH reaction generated in the intestine by the Map antigen in the pathogenesis of $\mathrm{CD}$. In addition, recent studies on the importance of CD1-presented mycobacterial lipid antigens in the host immune system (Watanabe et al. 2006) provide direction for future research on the pathogenesis of CD.

Epidemiological studies also suggest that the western diet is related to the incidence of CD (Lakatos 2006).

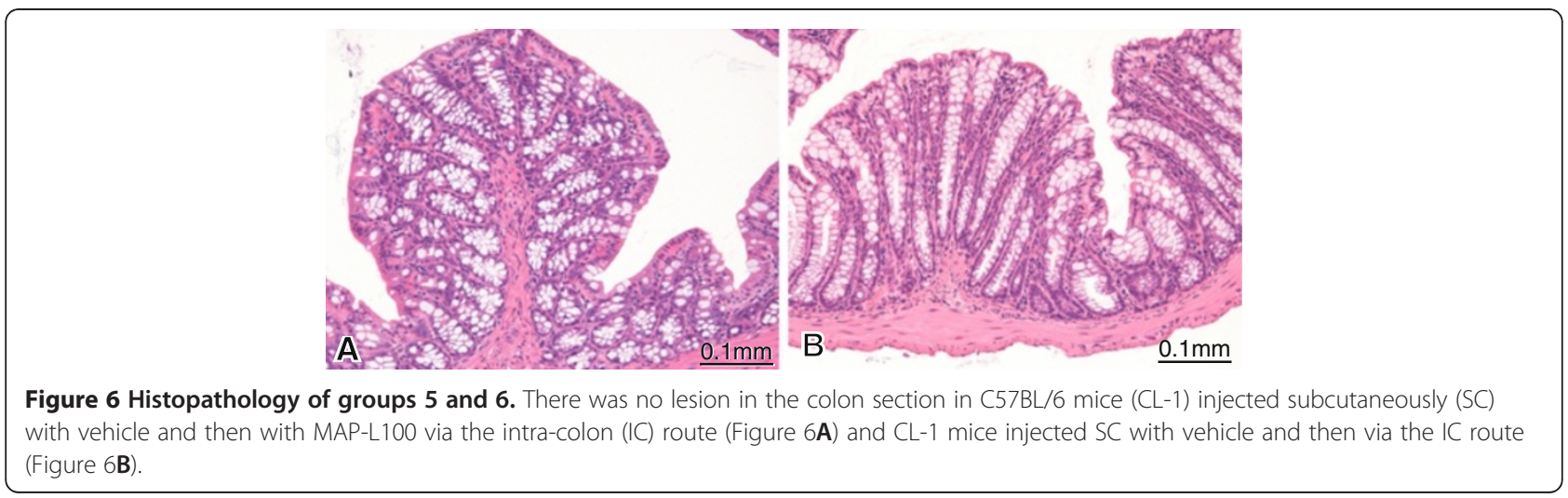


The probability that people having some genetic predisposition will ingest live Map in food is minimal, but the chance of exposure by heat-killed Map antigen may be very frequent. Although the heating process of dairy products eliminates live Map (Stabel 2000; Stabel and Lambertz 2004; Stabel et al. 1997), it may not eliminate hazards to human health. Of course, we should not neglect the possibility of human Map infection (Hermon-Taylor 2009; Singh et al. 2010).

\section{Conclusions}

The present study proposed a novel mouse model for CD-like colitis and the ability of Map antigen to induce necrotizing colitis, which may be the key to understanding the relationship between $\mathrm{CD}$ and Map. This model may help clarify the pathogenesis of $C D$, as well as other diseases with a suspected etiological relationship to Map (e.g., irritable bowel syndrome (Scanu et al. 2007), multiple sclerosis (Cossu et al. 2011), and type-1 diabetes mellitus (Paccagnini et al. 2009)). Also, this is the first evidence that mycobacterium antigen induces necrotizing colitis. In addition, the authors recommend that people who may have a genetic predisposition (Economou and Pappas 2008; Economou et al. 2004; Glasser and Darfeuille-Michaud 2008; Henderson et al. 2011; Lakatos 2009; Tsianos et al. 2012; Tuci et al. 2011; Umeno et al. 2011) to CD (i.e., if a relative has CD) should avoid dairy products possibly contaminated with the Map antigen (Eltholth et al. 2009; Foods 2010; Hermon-Taylor et al. 2000; Millar et al. 1996; Patel and Shah 2011) because no other measures for preventing CD are known.

\section{Methods}

\section{Antigen preparation}

Mycobacterium avium subspecies paratuberculosis (ATCC 19698) was grown in Middle brook 7H9 liquid medium (Difco Laboratories, MD, USA) enriched with BBL Middle brook OADC (Becton Dickinson, Tokyo, Japan) and $2 \mathrm{mg} / \mathrm{L}$ of mycobactin J (Allied Laboratory, MO, USA) for two weeks. Next, $90 \mathrm{ml}$ of the culture was centrifuged at 2,200xg for $20 \mathrm{~min}$, the supernatant was removed, and the culture was re-suspended in phosphate buffer saline (PBS). After washing twice with PBS, wet bacilli (1g wet weight) were collected. Surface lipophilic antigen was isolated by a previous method (Speer et al. 2006). The bacilli were suspended in $12 \mathrm{ml}$ of $80 \%$ ethanol by vortex at room temperature for $1 \mathrm{~min}$. The suspension was centrifuged, and the resulting supernatant was collected. The dried material weighed 20mg; thus, the concentration was calculated as $1.7 \mathrm{mg} / \mathrm{ml}$ in $80 \%$ ethanol. The material (Map-L antigen) was dissolved with 50\% ethanol and used as MAP-L100 antigen $(0.68 \mu \mathrm{g} / \mu \mathrm{l})$. Antigens serially diluted 10 times were used as MAP-L10 $(0.068 \mu \mathrm{g} / \mu \mathrm{l})$ and MAP-L1 antigen $(0.0068 \mu \mathrm{g} / \mu \mathrm{l})$. Preparation of the culture and isolation of the antigen were carried out in laboratory certified as a biosafety level 2 (BSL2-TS-49) in NIAH.

\section{Experimental animals}

C57BL/6Cr Slc female mice at 10 weeks old were purchased from Japan SLC, Inc., and kept in a specificpathogen-free (SPF) environment under the conditions described above. The mice were fed ad libitum during the experiments.

\section{Experiment procedure}

This study was carried out in strict accordance with the recommendations in the Guide for the Care and Use of Laboratory Animals of the National Institutes of Animal Health. The protocol was approved by the Committee of the Ethics of Animal Experiments of the NIAH (Permit Numbers: 08-118, 09-130 and A10-025), and all efforts were made to minimize suffering. All treatments were performed under general anesthesia with Avertin (2,2,-Tribromoethanol) (Arita et al. 2005). The mice were divided into six groups and injected twice with different antigens (Figure 1A). The primary injection was performed subcutaneously. The secondary antigen injections to the colon were performed through the trans-anal route with a fine urinary catheter (Atom Multipurpose Tube, $1.35 \mathrm{~mm}$ in diameter, Atom Medical Corporation, Tokyo). Feeding was stopped $24 \mathrm{~h}$ before the secondary injection. This experimental procedure was basically accorded to previously reported TNBS colitis model by Arita et al. (Arita et al. 2005), because of the the favorable reproducibility.

Group 1 mice, TNBS positive control group were treated subcutaneously with $2.5 \%$ TNBS in 50\% ethanol and then injected with $10 \%$ TNBS in ethanol by the transanal route. All mice in groups 2,3 , and 4 were subcutaneously injected with $25.5 \mu \mathrm{g} / 150 \mu \mathrm{l}$ of MAP-L antigen in $50 \%$ ethanol (Map-L100 antigen). Seven days after treatment, the same antigen with three different concentrations (2.5 (MAP-L100), 0.25 (MAP-L10), and 0.025 $\mu \mathrm{g}$ (MAP-L1)/150 $\mu \mathrm{l}$ in $50 \%$ ethanol) were injected into the colon. Group 5 mice were pretreated subcutaneously with $50 \%$ ethanol, and then $25 \mu \mathrm{g}$ of MAP-L100 antigen per $150 \mu \mathrm{l}$ in $50 \%$ ethanol was injected into the colon. Group 6 mice were treated with $50 \%$ ethanol by SC injection and then by injection into the colon as a nonantigen control. Five days after the injection, the mice were put down by carbon dioxide gas. Colon tissues were sampled and fixed in $20 \%$ buffered formalin solution for histopathological examination. The fixative was gently injected into the lumen of the intestine by syringe with a 21 gauge needle. 
All experiment protocols used in this study were approved by the Ethics Review Committee for Animal Experimentation of NIAH (approval Nos. 08-118 and 09-130).

\section{Histopathology}

Tissues fixed for three days were trimmed to be round slices and embedded in paraffin blocks. Sections were cut $4 \mu \mathrm{m}$ thick and stained with hematoxylin and eosin $(H \& E)$ and then observed under a microscope. The findings were recorded, and the degree of changes were expressed as 0 to 3 and made stacked bar graphs. (Figures A1-3).

\section{Abbreviations}

CD: Crohn's disease; UC: Ulcerative colitis; Map: Mycobacterium avium subsp. paratuberculosis; Ptb: Paratuberculosis; TNBS: 2,4,6-trinitrobenzene sulfonic acid; OADC: Oleic Acid-Albumin Fraction V-Dextrose-Catalase enrichment; SPF: Specific-pathogen-free.

\section{Competing interests}

The authors declare that they have no competing interests.

\section{Author's contributions}

$\mathrm{EM}, \mathrm{HO}, \mathrm{MH}$ and $\mathrm{MI}$ conceived and designed the experiments. SE purified the antigen. EM, SE, SY and TK performed the experiments. EM, HO, MH, SE and $\mathrm{MI}$ analyzed the data. EM, HO, MH, and SE contributed reagents, materials, or analysis tools. EM, SE, SY and MI wrote the paper. All authors read and approved the final manuscript.

\section{Acknowledgements}

This work was supported by Grants-in-Aid for Scientific Research from the Japanese Ministry of Education No. 23240061(to EM) and No. 20228005 (to H O), and the Bio-oriented Technology Research Advancement Institute (BRAIN) (to EM). We thank Mr. M. Kobayashi and Ms. M. Shimada for preparing excellent histopathological sections.

\section{Author details \\ ${ }^{1}$ Research Area of Pathology and Pathophysiology, National Institute of Animal Health, 3-1-5 Kan-nondai, Tsukuba 305-0856, Japan. ${ }^{2}$ Department of Veterinary Pharmacology Graduate School of Agriculture and Life Sciences, the University of Tokyo, Tokyo 113-8657, Japan. ${ }^{3}$ Laboratories of Immunology, School of Life and Environmental Science, Azabu University, Fuchinobe 1-17-71, Chuo-ku, Sagamihara, Kanagawa 252-5201, Japan. ${ }^{4}$ Center for Wildlife Health, Department of Forestry, Wildlife and Fisheries, the University of Tennessee, Knoxville, Tennessee 37996-1071, USA. ${ }^{5}$ Department of Pathology, the Jikei University School of Medicine, Minato-ku, Tokyo, Japan.}

Received: 12 September 2012 Accepted: 29 October 2012

Published: 8 November 2012

\section{References}

Abubakar I, Myhill D, Aliyu SH, Hunter PR (2008) Detection of Mycobacterium avium subspecies paratuberculosis from patients with Crohn's disease using nucleic acid-based techniques: a systematic review and meta-analysis. Inflamm Bowel Dis 14:401-410

Alonso-Hearn M, Molina E, Geijo M, Vazquez P, Sevilla I, Garrido JM, Juste RA (2009) Isolation of Mycobacterium avium subsp. paratuberculosis from muscle tissue of naturally infected cattle. Foodborne Pathog Dis 6:513-518

Arita M, Yoshida M, Hong S, Tjonahen E, Glickman JN, Petasis NA, Blumberg RS, Serhan CN (2005) Resolvin E1, an endogenous lipid mediator derived from omega-3 eicosapentaenoic acid, protects against 2,4,6-trinitrobenzene sulfonic acid-induced colitis. Proc Natl Acad Sci USA 102:7671-7676

Baumgart DC, Sandborn WJ (2007) Inflammatory bowel disease: clinical aspects and established and evolving therapies. Lancet 369:1641-1657
Behr MA, Kapur V (2008) The evidence for Mycobacterium paratuberculosis in Crohn's disease. Curr Opin Gastroenterol 24:17-21

Benchimol El, Fortinsky KJ, Gozdyra P, Van den Heuvel M, Van Limbergen J, Griffiths AM (2011) Epidemiology of pediatric inflammatory bowel disease: a systematic review of international trends. Inflamm Bowel Dis 17:423-439

Black CA (1999) Delayed type hypersensitivity: current theories with an historic perspective. Dermatol Online J 5:7

Chiodini RJ (1989) Crohn's disease and the mycobacterioses: a review and comparison of two disease entities. Clin Microbio Rev 2:90-117

Chiodini RJ, Van Kruiningen HJ, Merkal RS (1984) Ruminant paratuberculosis (Johne's disease): the current status and future prospects. Cornell Vet $74: 218-262$

Cossu D, Cocco E, Paccagnini D, Masala S, Ahmed N, Frau J, Marrosu MG, Sechi LA (2011) Association of Mycobacterium avium subsp. paratuberculosis with multiple sclerosis in Sardinian patients. PLoS One 6:e18482

Economou M, Pappas G (2008) New global map of Crohn's disease: Genetic, environmental, and socioeconomic correlations. Inflamm Bowel Dis 14:709-720

Economou M, Trikalinos TA, Loizou KT, Tsianos EV, loannidis JP (2004) Differentia effects of NOD2 variants on Crohn's disease risk and phenotype in diverse populations: a meta analysis. Am J Gastroenterol 99:2393-2404

Eltholth MM, Marsh VR, Van Winden S, Guitian FJ (2009) Contamination of food products with Mycobacterium avium paratuberculosis: a systematic review. J Appl Microbiol 107:1061-1071

Feller M, Huwiler K, Stephan R, Altpeter E, Shang A, Furrer H, Pfyffer GE, Jemmi T, Baumgartner A, Egger M (2007) Mycobacterium avium subspecies paratuberculosis and Crohn's disease: a systematic review and meta-analysis. Lancet Infect Dis 7:607-613

Foods NACoMCf (2010) Assessment of food as a source of exposure to Mycobacterium avium subspecies paratuberculosis (MAP). J Food Prot 73:1357-1397

Gill CO, Saucier L, Meadus WJ (2011) Mycobacterium avium subsp. paratuberculosis in dairy products, meat, and drinking water. J Food Prot 74:480-499

Glasser AL, Darfeuille-Michaud A (2008) Abnormalities in the handling of intracellular bacteria in Crohn's disease: a link between infectious etiology and host genetic susceptibility. Arch Immunol Ther Exp (Warsz) 56:237-244

Henderson P, van Limbergen JE, Wilson DC, Satsangi J, Russell RK (2011) Genetics of childhood-onset inflammatory bowel disease. Inflamm Bowel Dis 17:346-361

Hermon-Taylor J (2009) Mycobacterium avium subspecies paratuberculosis, Crohn's disease and the Doomsday scenario. Gut Pathog 1:15

Hermon-Taylor J, Bull TJ, Sheridan JM, Cheng J, Stellakis ML, Sumar N (2000) Causation of Crohn's disease by Mycobacterium avium subspecies paratuberculosis. Can J Gastroenterol 14:521-539

Jakobsen C, Wewer V, Urne F, Andersen J, Faerk J, Kramer I, Stagegaard B, Pilgaard B, Weile B, Paerregaard A (2008) Incidence of ulcerative colitis and Crohn's disease in Danish children: still rising or levelling out? J Crohns Colitis 2:152-157

Kirkwood CD, Wagner J, Boniface K, Vaughan J, Michalski WP, Catto-Smith AG Cameron DJ, Bishop RF (2009) Mycobacterium avium subspecies paratuberculosis in children with early-onset Crohn's disease. Inflamm Bowel Dis 15:1643-1655

Klanicova B, Slana I, Vondruskova H, Kaevska M, Pavlik I (2011) Real-time quantitative PCR detection of Mycobacterium avium subspecies in meat products. J Food Prot 74:636-640

Kobayashi K, Blaser MJ, Brown WR (1989) Immunohistochemical examination for mycobacteria in intestinal tissues from patients with Crohn's disease. Gastroenterol 96:1009-1015

Kobayashi K, Kaneda K, Kasama T (2001) Immunopathogenesis of delayed-type hypersensitivity. Microsc Res Tech 53:241-245

Lakatos PL (2006) Recent trends in the epidemiology of inflammatory bowel diseases: up or down? World J Gastroenterol 12:6102-6108

Lakatos PL (2009) Environmental factors affecting inflammatory bowel disease: have we made progress? Dig Dis 27:215-225

Loddenkemper C (2009) Diagnostic standards in the pathology of inflammatory bowel disease. Dig Dis 27:576-583

Lowe AM, Yansouni CP, Behr MA (2008) Causality and gastrointestinal infections: Koch, Hill, and Crohn's. Lancet Infect Dis 8:720-726

McClure HM, Chiodini RJ, Anderson DC, Swenson RB, Thayer WR, Coutu JA (1987) Mycobacterium paratuberculosis infection in a colony of stumptail macaques (Macaca arctoides). J Infect Dis 155:1011-1019 
Millar D, Ford J, Sanderson J, Withey S, Tizard M, Doran T, Hermon-Taylor J (1996) IS900 PCR to detect Mycobacterium paratuberculosis in retail supplies of whole pasteurized cows' milk in England and Wales. Appl Environ Microbiol 62:3446-3452

Momotani E, Romona NM, Yoshihara K, Momotani Y, Hori M, Ozaki H, Eda S, Ikegami M (2012) Molecular pathogenesis of bovine paratuberculosis and human inflammatory bowel diseases. Vet Immunol Immunopathol 148:55-68

Neuman MG, Nanau RM (2012) Inflammatory bowel disease: role of diet, microbiota, life style. Transl Res 160:29-44

Neurath M, Fuss I, Strober W (2000) TNBS-colitis. Int Rev Immunol 19:51-62

Nielsen SS, Toft N (2009) A review of prevalences of paratuberculosis in farmed animals in Europe. Prev Vet Med 88:1-14

Olsen I, Tollefsen S, Aagaard C, Reitan LJ, Bannantine JP, Andersen P, Sollid LM, Lundin KE (2009) Isolation of Mycobacterium avium subspecies paratuberculosis reactive CD4 T cells from intestinal biopsies of Crohn's disease patients. PLoS One 4:e5641

Over K, Crandall PG, O'Bryan CA, Ricke SC (2011) Current perspectives on Mycobacterium avium subsp. paratuberculosis, Johne's disease, and Crohn's disease: a review. Crit Rev Microbiol 37:141-156

Paccagnini D, Sieswerda L, Rosu V, Masala S, Pacifico A, Gazouli M, Ikonomopoulos J, Ahmed N, Zanetti S, Sechi LA (2009) Linking chronic infection and autoimmune diseases: Mycobacterium avium subspecies paratuberculosis, SLC11A1 polymorphisms and type-1 diabetes mellitus. PLoS One 4:e7109

Patel A, Shah N (2011) Mycobacterium avium subsp paratuberculosis-Incidences in milk and milk products, their isolation, enumeration, characterization, and role in human health. J Microbiol Immunol Infect 44:473-479

Peyrin-Biroulet L, Loftus EV Jr, Colombel JF, Sandborn WJ (2010) The natural history of adult Crohn's disease in population-based cohorts. Am J Gastroenterol 105:289-297

Phavichitr N, Cameron DJ, Catto-Smith AG (2003) Increasing incidence of Crohn's disease in Victorian children. J Gastroenterol Hepatol 18:329-332

Pierce ES (2009) Where are all the Mycobacterium avium subspecies paratuberculosis in patients with Crohn's disease? PLoS Pathog 5:e1000234

Raizman EA, Fetrow JP, Wells SJ (2009) Loss of income from cows shedding Mycobacterium avium subspecies paratuberculosis prior to calving compared with cows not shedding the organism on two Minnesota dairy farms. J Dairy Sci 92:4929-4936

Romero C, Hamdi A, Valentine JF, Naser SA (2005) Evaluation of surgical tissue from patients with Crohn's disease for the presence of Mycobacterium avium subspecies paratuberculosis DNA by in situ hybridization and nested polymerase chain reaction. Inflamm Bowel Dis 11:116-125

Sartor RB (2005) Does Mycobacterium avium subspecies paratuberculosis cause Crohn's disease? Gut 54:896-898

Scanu AM, Bull TJ, Cannas S, Sanderson JD, Sechi LA, Dettori G, Zanetti S, Hermon-Taylor J (2007) Mycobacterium avium subspecies paratuberculosis infection in cases of irritable bowel syndrome and comparison with Crohn's disease and Johne's disease: common neural and immune pathogenicities. J Clin Microbiol 45:3883-3890

Simmons A (2010) Crohn's disease: Genes, viruses and microbes. Nature 466:699-700

Singh AV, Singh SV, Singh PK, Sohal JS (2010) Is Mycobacterium avium subsp. paratuberculosis, the cause of Johne's disease in animals, a good candidate for Crohn's disease in man? Indian J Gastroenterol 29:53-58

Speer CA, Scott MC, Bannantine JP, Waters WR, Mori Y, Whitlock RH, Eda S (2006) A novel enzyme-linked immunosorbent assay for diagnosis of Mycobacterium avium subsp. paratuberculosis infections (Johne's Disease) in cattle. Clin Vaccine Immunol 13:535-540

Stabel JR (2000) Johne's disease and milk: do consumers need to worry? J Dairy Sci 83:1659-1663

Stabel JR, Lambertz A (2004) Efficacy of pasteurization conditions for the inactivation of Mycobacterium avium subsp. paratuberculosis in milk. J Food Prot 67:2719-2726

Stabel JR, Steadham EM, Bolin CA (1997) Heat inactivation of Mycobacterium paratuberculosis in raw milk: are current pasteurization conditions effective? Appl Environ Microbiol 63:4975-4977

Stabel JR, Palmer MV, Harris B, Plattner B, Hostetter J, Robbe-Austerman S (2009) Pathogenesis of Mycobacterium avium subsp. paratuberculosis in neonatal calves after oral or intraperitoneal experimental infection. Vet Microbiol 136:306-313 te Velde AA, Verstege MI, Hommes DW (2006) Critical appraisal of the current practice in murine TNBS-induced colitis. Inflamm Bowel Dis 12:995-999

Tsianos EV, Katsanos KH, Tsianos VE (2012) Role of genetics in the diagnosis and prognosis of Crohn's disease. World J Gastroenterol 18:105-118

Tuci A, Tonon F, Castellani L, Sartini A, Roda G, Marocchi M, Caponi A, Munarini A, Rosati G, Ugolini G, Fuccio L, Scagliarini M, Bazzoli F, Belluzzi A (2011) Fecal Detection of Mycobacterium avium Paratuberculosis Using the IS900 DNA Sequence in Crohn's Disease and Ulcerative Colitis Patients and Healthy Subjects. Dig Dis Sci 56:2957-2962

Umeno J, Asano K, Matsushita T, Matsumoto T, Kiyohara Y, lida M, Nakamura Y, Kamatani N, Kubo M (2011) Meta-analysis of published studies identified eight additional common susceptibility loci for Crohn's disease and ulcerative colitis. Inflamm Bowel Dis 17:2407-2415

Van Kruiningen HJ (1999) Lack of support for a common etiology in Johne's disease of animals and Crohn's disease in humans. Inflamm Bowel Dis 5:183-191

Veazey RS, Taylor HW, Horohov DW, Krahenbuhl JL, Oliver JL 3rd, Snider TG 3rd (1995) Histopathology of C57BL/6 mice inoculated orally with Mycobacterium paratuberculosis. J Comp Pathol 113:75-80

Vora P, Shih DQ, McGovern DP, Targan SR (2012) Current concepts on the immunopathogenesis of inflammatory bowel disease. Front Biosci (Elite Ed) 4:1451-1477

Wakefield AJ, Sawyerr AM, Dhillon AP, Pittilo RM, Rowles PM, Lewis AA, Pounder RE (1989) Pathogenesis of Crohn's disease: multifocal gastrointestinal infarction. Lancet 2:1057-1062

Wall S, Kunze ZM, Saboor S, Soufleri I, Seechurn P, Chiodini R, McFadden JJ (1993) Identification of spheroplast-like agents isolated from tissues of patients with Crohn's disease and control tissues by polymerase chain reaction. J Clin Microbiol 31:1241-1245

Watanabe Y, Watari E, Matsunaga I, Hiromatsu K, Dascher CC, Kawashima T, Norose Y, Shimizu K, Takahashi H, Yano I, Sugita M (2006) BCG vaccine elicits both T-cell mediated and humoral immune responses directed against mycobacterial lipid components. Vaccine 24:5700-5707

Wirtz S, Neufert C, Weigmann B, Neurath MF (2007) Chemically induced mouse models of intestinal inflammation. Nat Protoc 2:541-546

doi:10.1186/2193-1801-1-47

Cite this article as: Momotani et al:: Mycobacterium avium subsp. paratuberculosis lipophilic antigen causes Crohn's disease-type necrotizing colitis in Mice. SpringerPlus 2012 1:47.

\section{Submit your manuscript to a SpringerOpen ${ }^{\odot}$ journal and benefit from:}

- Convenient online submission

$\checkmark$ Rigorous peer review

- Immediate publication on acceptance

- Open access: articles freely available online

- High visibility within the field

- Retaining the copyright to your article

Submit your next manuscript at $>$ springeropen.com 